\title{
The impact of the optical radiation spectrum of artificial lighting on the milk producing ability of cows
}

\author{
N.L. Olin ${ }^{*}$, E.N. Efremova, A.M. Niyazov, and P.L. Lekomtsev \\ Izhevsk State Agricultural Academy, Studencheskaya Street, 11, 426069, Izhevsk, Russia
}

\begin{abstract}
Artificial lighting is of considerable importance in livestock industry. If there is sufficient light flux and optimal spectral composition, it can have a substantial impact on the comfortable condition of cows, and, as a result, on milk producing ability. The sensitivity of the cow's eye to optical radiation is varied in the range of the visible spectrum, and its visual apparatus is adapted to recognize natural different types of feed. The leaves of plants take up visible radiation in the red and blue regions of the spectrum, while they reflect intensely in the near-infra-red region. Consequently, cows, having the ability to perceive near-infrared radiation, can give favor to higher-quality feed, the consumption of which, among other things, will increase milk producing ability. The findings of the studies demonstrate that the cow's eye reacts to near-infrared radiation, and the combined lighting contributes to a more adequate behavior of the animals, which in turn has a positive effect on milk producing ability.
\end{abstract}

\section{Introduction}

The problems of energy efficiency and energy saving have become topical in modern lighting engineering. The process of mass introduction of energy-saving lighting products has obtained an additional motivator for development, due to the appearance of new emitters - LEDs.

The wide range of LED lamps offered, in most cases, have a variety of lighting features, which do not always provide specified parameters.

The energy-saving effect in modern animal husbandry technology is reached owing to the scientifically grounded and sufficient light flux, as well as the optimal spectral composition, which ensures comfortable conditions for keeping animals and obtaining maximum productivity from them.

It is an acute task to create a promising lighting device to scientifically justify the light flux and the adjustability of the spectral composition of radiation in conformance with the spectral sensitivity of the eyes of animals.

Artificial lighting is of significant importance in livestock industry. It has a considerable impact on milk producing ability and animal health, if it ensures the most comfortable conditions for the animals, both during the day and at night.

\footnotetext{
* Corresponding author: nik-olin@yandex.ru
} 
Being an active physiological irritant of the body, light modifies the metabolism of proteins, fats, carbohydrates, minerals and energy in general, depending on the intensity, duration of exposure and spectral composition, to affect the physiological condition and productivity of cows. The average length of daylight varies from 6 to 12 hours, and even in modern cowsheds there is not enough natural light during the stall-feeding period. The implementation of new technologies helps to increasingly isolate cows from the natural environment. Livestock houses are usually not heated. Thus, window openings in them are sought to be made as small as possible to reduce heat transfer, which contributes to a considerable reduction in natural illumination inside the premises. Therefore, a considerable amount of work on farms is conducted precisely during the period when the natural length of the day is sharply reduced.

For this reason, artificial light sources are applied together with natural lighting in the technological processes of livestock production.

During the design and construction of livestock houses, the light factor is considered. It means that the ratio of the space of windows to the floor area is measured. Meanwhile, it is believed that on dairy farms this ratio should be 1:10-1:15. Nevertheless, such guidelines can be seen as purely indicative, and the standardization of illumination in lux is more objective. Therefore, the illumination in the animal house is a essential external factor, and its degree depends not only on the seasons of the year, but also on artificial sources and structural features of houses.

The optical radiation, which is proportional to the sensitivity of the human eye, is a kind of electromagnetic vibrations. It occupies a section from 380 to 780 nanometers from the entire wavelength range. In this visible part of the spectrum, the eye feels color differentlyfrom red to purple. It is known that the biological receiver of optical radiation has unequal sensitivity to different parts of the spectrum. There is also reliable data to show that some animals have the ability to sense electromagnetic radiation with the help of vision beyond the visible range [1]

Up-to-date lighting systems for livestock houses use a variety of radiation sources. These can be incandescent lamps, fluorescent lamps or promising LED radiation sources. Using lamps, it is available to carry out systems of general or combined lighting. The general lighting system consists of uniform and localized lighting. Along with the general lighting system, local lighting can be applied in the houses, designed to increase the illumination of workplaces. Local and general lighting, used together, form a combined lighting system. In livestock houses, a system of general uniform or localized lighting is most often used. The use of LED radiation sources enables the realization of a lamp that combines both systems.

The standardized lighting parameters in the houses can be provided both by working lighting fixtures and by the joint action of safety lighting fixtures with them. If required, some of the working or emergency lighting fixtures can be used for after-hours lighting.

The considerable role of light as a physiological stimulus is emphasised by the fact that in the course of evolution higher animals got special light receptors-eyes. Light, acting on light-sensitive cells, triggers excitation processes. With the help of electrical signals, they spread along the optic nerves to the perceiving centers of the cerebral cortex. The presence or absence of lighting stimulates or inhibits the work of the endocrine system, on which most of the body's functions and its vital activity as a whole depend. The effect of light on the productivity of animals, as well as on their resistance to adverse factors, is defined by its intensity, duration, frequency and spectral composition of illumination. Individual parts of the radiation spectrum affect the neuromuscular apparatus of animals differently. It is also recognized that photosensitive skin cells, nerve cells and the brain can participate in the perception of radiation in addition to the eyes. Moreover, the light is absorbed directly by the blood. 
In the adaptation process to external conditions, under the influence of alternating periods of day and night, animals have formed a rhythmic change in the processes of vital activity, which is called photoperiodism. The manifestation of sexual reflexes, the growth and development of offspring, metabolism, milk secretion is regulated in animals by the light regime. The visible radiation affects the body reflexively through the visual organs and partially through the nerve endings in the skin. As a result, it stimulates photochemical processes, improves the function of the cardiovascular system and affects the condition of the central nervous system, increasing the activity of the cerebral cortex.

When intense and prolonged lighting increases the tone of the neuromuscular apparatus, resulting in enhanced motor activity. Lack of lighting, by contrast, inhibits behavioral reactions and metabolism, animals move less and rest more.

The choice of a light source for a livestock house is related to its biological effect on the body of farm animals, the level and complexity of the work performed by the service staff, as well as technical and economic indicators.

Many studies of the effect of light modes on the animal body are related to an increase in illumination and the duration of the light period. There is clearly insufficient accumulated experience on the biological role of the spectral composition of radiation. The study of the influence of the spectral composition of the radiation of light sources on the behavior and milk producing ability of cows is of significant interest.

The visual system of most mammals covers the spectral range from about 380 to 780 $\mathrm{nm}$. The researches of many authors indicate that the effect of radiation sources of various spectral composition on animals, in particular cows, is not fully considered and does not have a sufficiently complete explanation. Thus, the study of the use of modern lighting installations with different spectral parameters of radiation has an academic value and practical significance.

Many animals, herbivores, in the course of evolution have developed protective mechanisms to provide them with an advantage in the competitive struggle for survival and reproduction of offspring. One of these mechanisms is twilight vision, which promotes the fact that the spectral sensitivity of the visual organs of animals is optimal in the field of recognition of the food base. As for cows, the natural feed base is green feed. It is recognized that the leaves of almost all plants produce chlorophyll under the influence of sunlight. The maximum absorption of radiation by chlorophyll is in the red and blue regions of the spectrum (Fig. 1). 


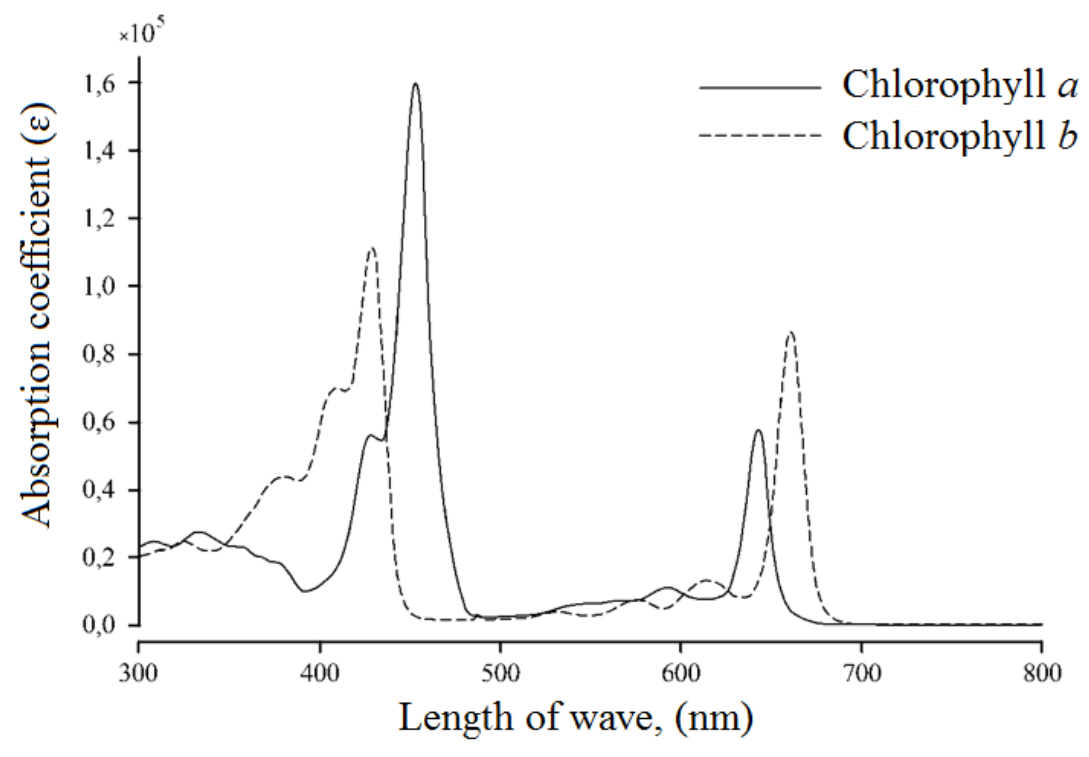

Fig. 1. The maximum absorption of chlorophyll of $\boldsymbol{a}$ and $\boldsymbol{b}$ type.

Chlorophyll $\boldsymbol{a}$ has an absorption maximum in the red region of the spectrum in the range of $660-663 \mathrm{~nm}$ and in the blue region in the range of $428-430 \mathrm{~nm}$. Chlorophyll $\boldsymbol{b}$ absorbs light in the range of 642-644 and $452-455 \mathrm{~nm}$. Thus, in the visible part of the radiation spectrum, the leaves have a much lower reflectivity. Although in the region of near-infrared radiation (with a length of more than $700 \mathrm{~nm}$ ), their reflective properties increase sharply (Fig. 2).

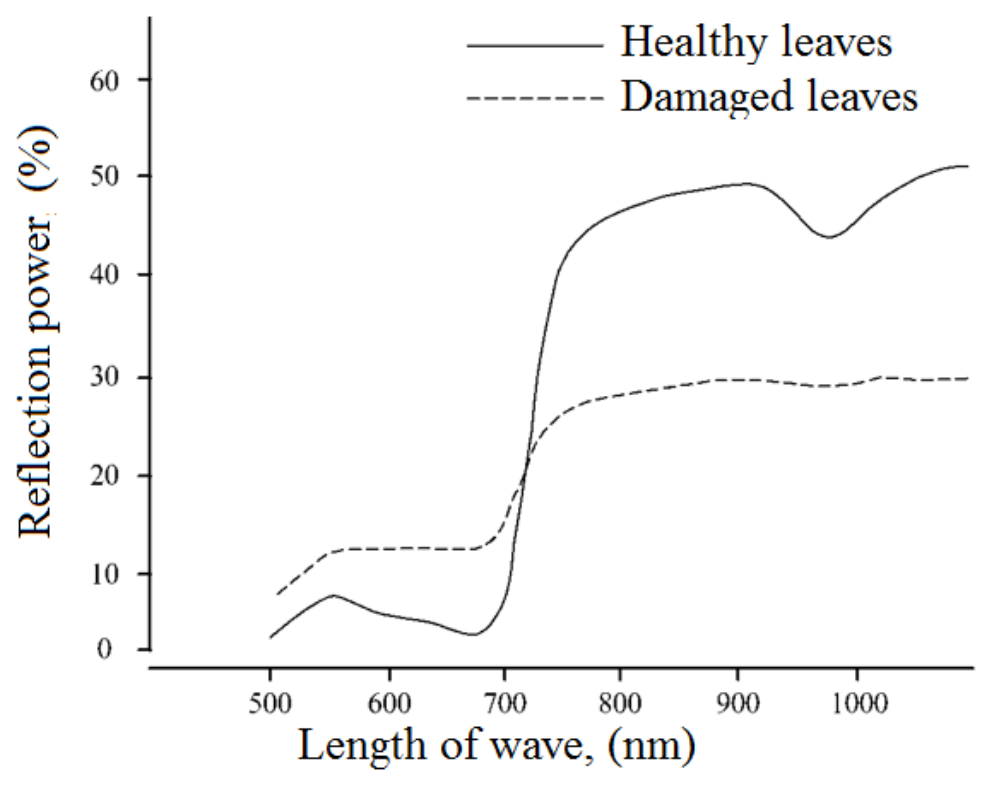

Fig. 2. Spectral reflectivity of healthy and damaged leaves. 
Moreover, healthy and damaged leaves reflect radiation in the visible and near-infrared regions of the spectrum differently. Damaged leaves reflect visible radiation more intensely, and healthy leaves reflect infrared radiation [2] Consequently, cows, having the ability to perceive near-infrared radiation, may prefer higher-quality feed, the consumption of which, among other things, will enhance milk producing ability. Other factors affecting feed consumption, as well as behavioral reactions that reduce productivity, is the irritating effect of optical radiation in various parts of the spectrum. To test this hypothesis, tests were performed.

\section{Materials and methods}

Like other animals with the ability for higher nervous activity, cows are able to respond to external irritating factors, such as bright light, sharp sound, too high or too low ambient temperature, the presence of other animals in their personal space, and so on. However, the type of reaction and its intensity can negatively affect the productive indicators. Thus, two groups of animals were chosen to obtain reliable research results. In each of them, the animals correspond to one of the types of higher nervous activity: "strong untroubled mobile" or "strong troubled". For determining the types of higher nervous activity, the method of observing the behavior of cows was used. The findings are expressed qualitatively and quantitatively. The behavior of all cows of group I was characterized by a calm relationship to other animals. The cows showed curiosity to strangers (sniffing), after which they calmly continued to take food; they reacted positively to touching (stroking). After the walk, the animals of group I took their places without human interference. The animals of group II chose to avoid meeting with stronger specimens, gave up their place and waited until they left. At night, they got up when the livestock breeders appeared. They took their place unwillingly after the walk. They reacted inadequately to touching, showed concern. Most of the cows showed raised anxiety on the effect of any stimulus. For behavioral analysis, each of the groups was subdivided into an experimental and a control group. For the first one, lighting with an experimentally chosen spectral composition was used, for the second - ordinary lighting used in the cowshed.

The microclimate settings were studied according to generally accepted methods using the following devices: air temperature-alcohol thermometer; relative humidity - August psychrometer; air velocity-manual winged anemometer ASO-3; illumination and spectral composition of radiation-CEM DT-1300 luxmeter with a set of light filters. LEDs used in research: LED (Infrared) I-K IR120-1-G-850; LED (Red) LXHL-R1E; LED (Yellow) LXHL-YEA1E; LED (Green) LXHL-G1E; LED (Blue) LXHL-B1E; LED (Ultraviolet) KW-UV-3W-B; LED (White-3000K) LXHL-WWE. Lighting installations were also formed from them in the future. The technology of keeping cows is tether-based with the use of wooden floors with a litter of sawdust, mobile feed distribution, automated watering and manure removal. In the summer, pasture and camp maintenance is used. The type of feeding is accepted on the farm (silage - concentrate-hay). For the exclusion of the influence of other disturbing factors, the studies were performed at a comfortable temperature (daily fluctuations from $+14 \mathrm{C}$ to $+17 \mathrm{C}$ ) in cloudy weather. In order to determine the sensitivity of the cow to the spectral composition of radiation, a study of the vegetative pupillary reflex was used. The dimensions were recorded visually, using a scale ruler. The amount of milk yield of cows was defined according to the data of control milkings. 


\section{In-house studies}

The pilot studies were divided into two groups. The first group consisted of studies of the reaction of the pupil of the cow's eye to a radiation source with a certain spectrum. The second group of studies involves the study of behavioral reactions of cows under lighting installations with different spectral composition.

The pupil sizes of the experimental cows in natural light were on average: width-1.79 $\mathrm{cm}$, height $-1.33 \mathrm{~cm}$. The illumination of the cow's eye was made three times from a distance of $50 \mathrm{~cm}$. The illumination value for each LED at this distance was determined to be the same-50 lux, using a parametric current stabilizer. It was monitored by a luxmeter using a light filter. The findings of studies of the eye's reaction to various radiation spectra are shown in Table 1.

Table 1. The size of the pupil under the exposure of the radiant (width $\times$ height, $\mathrm{cm}$ ).

\begin{tabular}{|l|c|l|l|l|l|l|l|}
\hline \multirow{2}{*}{$\begin{array}{l}\text { Experimen } \\
\text { tal group }\end{array}$} & \multicolumn{9}{|c|}{ Radiants } \\
\cline { 2 - 8 } & $\begin{array}{l}\text { I-K IR120-1- } \\
\text { G-850 }\end{array}$ & $\begin{array}{l}\text { LXHL- } \\
\text { R1E }\end{array}$ & $\begin{array}{l}\text { LXHL- } \\
\text { YEA1E }\end{array}$ & LXHL-G1E & LXHL-B1E & $\begin{array}{l}\text { KW-UV- } \\
3 W-B\end{array}$ & $\begin{array}{l}\text { LXHL- } \\
\text { WWE }\end{array}$ \\
\hline Group I & $1.49 \times 1.11$ & $1.48 \times 1.10$ & $1.59 \times 1.17$ & $1.70 \times 1.25$ & $1.78 \times 1.33$ & $1.80 \times 1.34$ & $1.57 \times 1.16$ \\
\hline Group II & $1.48 \times 1.09$ & $1.47 \times 1.09$ & $1.59 \times 1.18$ & $1.71 \times 1.27$ & $1.79 \times 1.34$ & $1.79 \times 1.33$ & $1.56 \times 1.15$ \\
\hline
\end{tabular}

The above parameters indicate that the cow's pupil reacts weakly to the radiant of the green, blue and ultraviolet spectrum, and the strongest reaction is found to the radiants of the red and infrared spectrum.
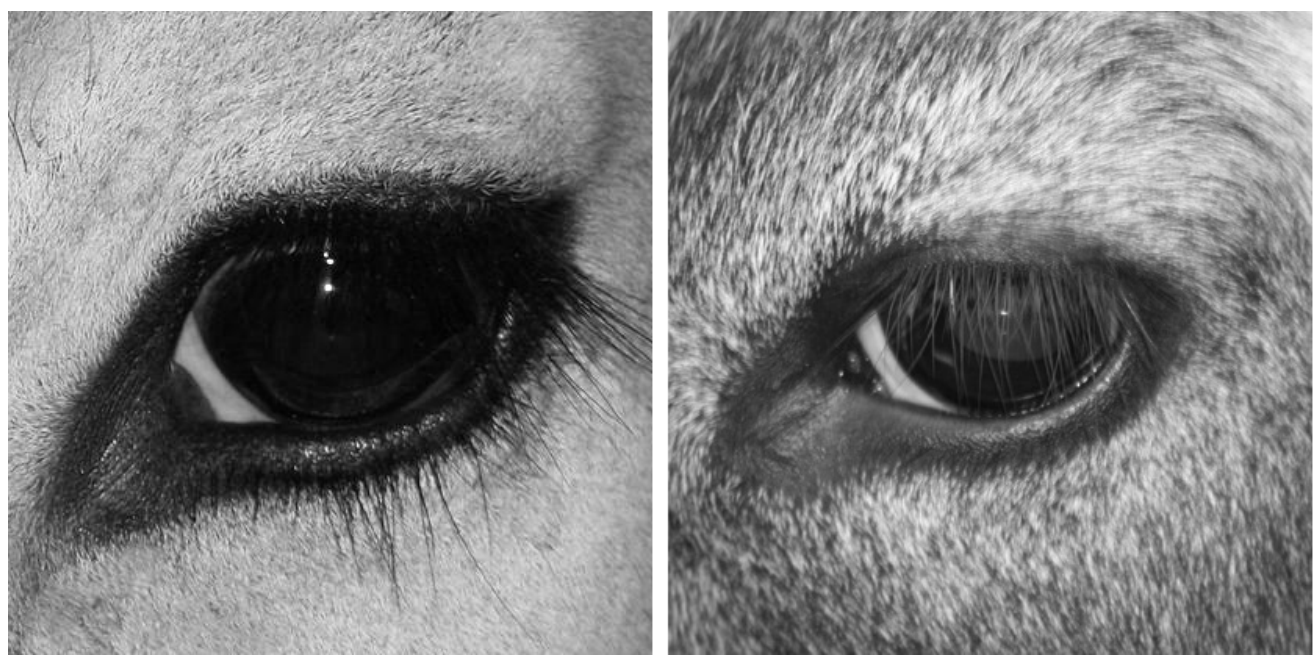

Fig. 3. The cow's eye within the experiment.

During the experiment for behavioral analysis, the following ethological reactions were considered, indicating a comfortable condition of the animal: feed consumption, drinking, chewing, lying down, defecation, urination. The study of environmental parameters was performed using a video recorder. The data of daily monitoring of behavioral reactions when using the existing lighting system is shown in Table 2, with a lighting system with an experimental spectral composition - in Table 3.

Table 2. Daily ethogram of cows by groups in the stall period with the current lighting system.

\begin{tabular}{|l|c|c|}
\hline \multirow{2}{*}{ Indicator } & \multicolumn{2}{|c|}{ Group of animals } \\
\cline { 2 - 3 } & $\mathrm{I} \quad \mathrm{II}$ \\
\hline
\end{tabular}




\begin{tabular}{|l|c|c|c|c|}
\hline & $\min$. & $\%$ & $\min$. & $\%$ \\
\hline Feed consumption & 402 & 27.91 & 467.5 & 32.46 \\
\hline Drinking & 27.4 & 1.90 & 24.7 & 1.71 \\
\hline Chewing period & 561 & 38.95 & 532.5 & 36.97 \\
\hline Defecation, frequency & 12.5 & - & 13.16 & - \\
\hline Urination, frequency & 8.83 & - & 8.67 & - \\
\hline Lying down, total & 480 & 33.33 & 412.5 & 28.64 \\
\hline
\end{tabular}

The above information suggests that the cows of the first group spent less time on consuming feed than the cows of the second group, while the animals consumed all the feed laid in the feeders were not distracted by extraneous irritants. At the same time, the cows of the second group often stopped their feed consumption when the service staff appeared, when the manure conveyor was turned on and the lighting mode changed. As a result, the volume of feed consumed by the second group was less than that of the first group. The chewing period of the cows of the first group was longer, most of the time of which, the cows were in the lying position. The cows of the second group rested less and spent less time on chewing, which may affect the lower digestibility of feed and negatively affect milk producing ability.

Table 3. Daily etogram of cows by groups in the stall period under a lighting system with an experimental spectral composition.

\begin{tabular}{|c|c|c|c|c|}
\hline \multirow{3}{*}{ Indicator } & \multicolumn{4}{|c|}{ Group of animals } \\
\hline & \multicolumn{2}{|c|}{ I } & \multicolumn{2}{|c|}{ II } \\
\hline & $\min$. & $\%$ & $\min$. & $\%$ \\
\hline Feed consumption & 405 & 28.13 & 431.4 & 29.96 \\
\hline Drinking & 26.6 & 1.85 & 25.5 & 1.77 \\
\hline Chewing period & 564 & 39.17 & 551.2 & 38.28 \\
\hline Defecation, frequency & 12.3 & - & 12.5 & - \\
\hline Urination, frequency & 8 & - & 9.1 & - \\
\hline Lying down, total & 482.1 & 33.48 & 441.6 & 30.67 \\
\hline
\end{tabular}

In the case of using lighting with an experimental special composition, the cows of the first group spent slightly more time on feed consumption. Meanwhile, the cows of the second group were less distracted by extraneous irritants, which enabled them to consume all the feed in a shorter period of time. The chewing period of the cows of the second group has grown, compared with the use of conventional lighting, the time spent by the cows in the lying position has also grown. These facts demonstrate that the parameters of comfortable behavior of cows of the second group have become more pronounced. Although the cows of the first group, due to the balance of their type of higher nervous activity, practically did not change the indicators of adequate behavior.

\section{Conclusion}

The research of the spectral composition of the radiation sources from the optical range or a certain part of the spectrum on the perception of lighting by animals requires considering the conditions of their habitat and the specifics of the structure of the eye. Most animals are distinguished by color vision. However, it has a varied degree of light perception of different parts of the optical radiation spectrum.

Therefore, the application of lighting devices with pilot spectral composition promoted the adequate behavior of the animals, which had a positive effect on the milk producing ability. 


\section{References}

1. S. Izhboldina, Mil \& m hus, 1, 30-32 (2007)

2. N.L. Olin, Sc 1, 1, 13-22 (2016)

3. OSN-APK 2.10.24.001-04. Lighting standards for agricultural enterprises, buildings and structures. Ministry of Agriculture of Russia, Moscow, FGNU SPC "Giproniselkhoz", (2004)

4. E. Rabinovich, A. A. Nichiporovich, E. V. Shpolsky; Photosynthesis 2, 652 (Moscow, Publishing house of foreign literature, 1953)

5. Set of rules SP 52.13330.2016 "SNiP 23-05-95*. Natural and artificial lighting". Updated version of SNiP 23-05-95* (Approved by the order of the Ministry of Construction and Housing and Communal Services of the Russian Federation of November 7, 2016.N 777/ effective from May 8, 2017).

6. V.M. Yurkov, The impact of light on the resistance and productivity of animals, 192 (Moscow, Rosagropromizdat, 1991)

7. G.E. Dahl \& D. Petitclerc, J of An Sc 81, 11-17 (2003)

8. C. Hogg, T J of ex b, 214 (12), 2014-2019 (2011)

9. J. Hulsen, Cow Signals, Roodbont Publishers (2005) 